\title{
Salame tipo italiano elaborado com culturas starters nativas
}

\author{
Fermented italian sausage elaborated with native starter cultures
}

\section{Andréia CIROLINI ${ }^{1 *}$, Leadir Lucy Martins FRIES ${ }^{1}$, Nelcindo Nascimento TERRA ${ }^{1}$, Liana Inês Guidolin MILANI ${ }^{1}$, Diala URNAU ${ }^{1}$, Bibiana Alves dos SANTOS $^{1}$, Giovanna Dotta CERVO ${ }^{1}$, Ana Paula de Souza REZER ${ }^{1}$}

\section{Resumo}

A pesquisa teve como objetivo acrescentar culturas starters nativas em salame tipo Italiano e avaliar o desempenho frente a culturas comerciais quanto às características microbiológicas, físico-químicas e sensoriais. As culturas utilizadas foram Staphylococcus xylosus, isolado de salames coloniais, e Lactococcus lactis ssp. lactis, isolado de um produto lácteo e fermentado em meio de cultura de plasma suíno. Elaboraram-se os seguintes tratamentos: T1 - adição de starters comerciais (Staphylococcus xylosus e Lactococcus lactis ssp. lactis); T2 - mistura de Staphylococcus xylosus isolado mais Lactococcus lactis ssp. lactis comercial; T3 - mistura de Lactococcus lactis ssp. lactis isolado mais Staphylococcus xylosus comercial; e T4 - Staphylococcus xylosus e Lactococcus lactis ssp. lactis, ambos isolados. Os tratamentos apresentaram uma queda de $\mathrm{pH}$ significativa e também uma redução na Aw, garantindo uma segurança microbiológica aos produtos. Em relação à oxidação lipídica, os tratamentos que continham Staphylococcus xylosus isolados de salames artesanais apresentaram valores menores que os outros tratamentos. Os salames elaborados com Staphylococcus xylosus e Lactococcus lactis ssp. lactis, ambos isolados, apresentaram melhores resultados sensoriais quando comparados com salames elaborados com culturas starters comerciais. Portanto, a adição de culturas starters nativas pode ser utilizada na elaboração de salames, proporcionando produtos seguros e com flavor diferenciado.

Palavras-chave: culturas starters nativas; salame; Staphylococcus xylosus; Lactococcus lactis ssp. lactis.

\begin{abstract}
The objective of this paper was to add native starter cultures in fermented Italian sausages and evaluate the performance compared to commercial cultures in terms of microbiological and physicochemical parameters and sensorial characteristics. The cultures used were Staphylococcus xylosus, isolated from colonial sausages, and Lactococcus lactis ssp. lactis isolated from a dairy product and fermented in pork plasma medium. The following treatments were performed: T1 - addition of commercial starters (Staphylococcus xylosus and Lactococcus lactis ssp. lactis); T2 - mixture of isolated Staphylococcus xylosus plus commercial Lactococcus lactis ssp. lactis; T3 - mixture of isolated Lactococcus lactis ssp lactis plus commercial Staphylococcus xylosus; and T4 - Staphylococcus xylosus and Lactococcus lactis ssp lactis both isolated. The treatments showed a significant decrease of $\mathrm{pH}$ and reduction in the Aw ensuring microbiological safety to the products. With regard to lipid oxidation, the treatments that contained isolated strains of Staphylococcus xylosus presented significantly lower values than the other treatments. The sausages elaborated with Staphylococcus xylosus and Lactococcus lactis ssp lactis, both strains isolated, presented better sensorial results than the sausages elaborated with commercial starter cultures. Therefore, the addition of native starter cultures can be used in the elaboration of fermented Italian sausages providing safe products with differentiated flavor.

Keywords: native starter cultures; sausages; Staphylococcus xylosus; Lactococcus lactis ssp. lactis.
\end{abstract}

\section{Introdução}

A fermentação é uma das mais antigas tecnologias utilizadas para conservação dos alimentos. No passado, a fermentação era um resultado espontâneo da microflora natural da carne e do ambiente. Entretanto, a fermentação descontrolada pode produzir produtos inferiores ou mesmo inseguros para o consumo (ESSID et al., 2007).

Em 1957, ocorreu a introdução comercial de culturas puras de microrganismos, chamadas culturas starters, aos produtos fermentados permitindo uniformidade entre os produtos, redução do tempo de fermentação e uma alta conservação do produto (VURAL, 1998).
Duas categorias de microrganismos são comumente utilizadas como culturas starters, ou seja, as bactérias ácido lácticas que promovem a segurança e estabilidade do produto e Staphylococccus coagulase negativa responsáveis por estabilizar a cor, prevenir a rancificação e realçar compostos aromáticos dos produtos cárneos (DROSINOS et al., 2005).

Terra (2003) destaca que a produção de salame do Brasil depende da importação integral das culturas starters, o que acarreta um desequilíbrio da balança comercial além de levar ao esquecimento do sabor genuinamente brasileiro.

Recebido para publicação em 2/6/2008

Aceito para publicação em 7/3/2009 (003551)

${ }^{1}$ Departamento de Tecnologia e Ciência dos Alimentos, Centro de Ciências Rurais, Universidade Federal de Santa Maria - UFSM, CEP 97105-900, Santa Maria - RS, Brasil,

E-mail: deiacirolini@yahoo.com.br

${ }^{*}$ A quem a correspondência deve ser enviada 
Greco et al., (2005) e Moretti et al., (2004) acrescentam que salames artesanais apresentam melhores características sensoriais que salames industriais, devido à composição e atividade metabólica da microflora indígena.

Portanto, o presente trabalho teve como finalidade acrescentar culturas starters nativas, em salame tipo Italiano e avaliar seu desempenho frente a culturas comerciais, quanto a suas características microbiológicas, físico-químicas e sensoriais.

\section{Material e métodos}

\subsection{Culturas iniciadoras}

As cepas usadas neste estudo foram a cultura de Staphylococcus xylosus, anteriormente isolada de salames coloniais da região central do Estado do Rio Grande do Sul, multiplicada em ágar Baird Parker (CIROLINI et al., 2007a); a cultura de Lactococcus lactis ssp. lactis, isolada anteriormente de um produto lácteo fermentada em meio de cultura de plasma suíno (CIROLINI et al., 2007b); e as cepas Lactococcus lactis ssp. lactis, doada pela Fundação André Tosello, Campinas - SP e Floracarn SX (Chr. Hansen), contendo o microrganismo Staphylococcus xylosus.

\subsection{Preparo do salame}

As amostras de salame foram elaboradas de acordo com a seguinte formulação: pernil suíno $\left(600 \mathrm{~g} . \mathrm{kg}^{-1}\right)$, retalho bovino (200 g. $\left.\mathrm{kg}^{-1}\right)$, toicinho congelado $\left(200 \mathrm{~g} \cdot \mathrm{kg}^{-1}\right)$, cloreto de sódio $\left(30\right.$ g. $\left.\mathrm{kg}^{-1}\right)$, glicose $\left(5 \mathrm{~g} . \mathrm{kg}^{-1}\right)$, sacarose $\left(5 \mathrm{~g} \cdot \mathrm{kg}^{-1}\right)$, mistura comercial de cura, contendo nitrato e nitrito de sódio $\left(3 \mathrm{~g} . \mathrm{kg}^{-1}\right)$, ascorbato de sódio (2,5 g. $\left.\mathrm{kg}^{-1}\right)$, pimenta branca $\left(2 \mathrm{~g} \cdot \mathrm{kg}^{-1}\right)$, alho $\left(5 \mathrm{~g} \cdot \mathrm{kg}^{-1}\right) \mathrm{e}$ noz moscada $\left(0,2 \mathrm{~g} \cdot \mathrm{kg}^{-1}\right)$. A carne suína foi moída em disco de $12 \mathrm{~mm}$ e a carne bovina em disco de $8 \mathrm{~mm}$. Após a moagem, as carnes sofreram a adição de cloreto de sódio e foram misturadas em misturadeira durante 3 minutos para a extração de proteínas miofibrilares. A seguir, foram adicionados os demais ingredientes, com exceção do ascorbato de sódio que foi acrescentado por último (TERRA, 2003).

Após a mistura, porções iguais de massa foram divididas, originando os seguintes tratamentos: Tratamento 1 (T1), inoculado com starters comerciais de Staphylococcus xylosus (Floracarn SX, Chr. Hansen) e Lactococcus lactis ssp. lactis (Fund. André Tosello); Tratamento 2 (T2), mistura de Staphylococcus xylosus isolado (CIROLINI et al., 2007a) mais Lactococcus lactis ssp. lactis comercial (Fund. André Tosello); Tratamento 3 (T3), mistura de Lactococcus lactis ssp. lactis isolado (CIROLINI et al., 2007b) mais Staphylococcus xylosus comercial (Floracarn SX, Chr. Hansen); e Tratamento 4 (T4), inoculado com starters isolados de Staphylococcus xylosus (CIROLINI et al., 2007a) $e$ Lactococcus lactis ssp. lactis (CIROLINI et al., 2007b). A matériaprima apresentou uma contagem de bactérias aeróbias mesófilas de $1,3 \times 10^{4} \mathrm{UFC} . \mathrm{g}^{-1}$, sendo a quantidade de cultura starter adicionada de $10^{6}$ UFC.g $^{-1}$.

A massa cárnea dos tratamentos foi embutida em tripas artificiais de colágeno, com $60 \mathrm{~mm}$ de diâmetro e cortada em peças de aproximadamente $15 \mathrm{~cm}$ de comprimento. Após o embutimento, as amostras foram submetidas a um banho em solução de sorbato de potássio (20\%) e encaminhadas para a câmara climatizada, com temperatura e umidade relativa controlada, onde permaneceram até atingir uma atividade de água de 0,87 . A programação de temperatura e umidade relativa ( $\mathrm{T}^{\circ} / \mathrm{UR} \%$ ) foram as seguintes: primeiro dia, temperatura $25^{\circ} \mathrm{C} / \mathrm{UR} 95 \%$; segundo dia, $24^{\circ} \mathrm{C} / 93 \%$; terceiro dia, $23^{\circ} \mathrm{C} / 90 \%$; quarto dia, $22^{\circ} \mathrm{C} / 85 \%$; quinto dia, $21^{\circ} \mathrm{C} / 80 \%$; sexto dia, $20{ }^{\circ} \mathrm{C} / 75 \%$; e do sétimo dia em diante, $18{ }^{\circ} \mathrm{C} / 75 \%$. Concluída a fabricação, retiraram-se as tripas e as peças dos embutidos fermentados foram embaladas a vácuo e armazenadas à temperatura ambiente.

\subsection{Avaliação microbiológica}

Foram coletadas porções de $25 \mathrm{~g}$ de salame, que foram homogeneizadas com $225 \mathrm{~mL}$ de água peptonada $(0,1 \%)$ em Bag Mixer, por 2 minutos. Em seguida, foram feitas sucessivas diluições decimais.

\section{Contagem de bactérias ácido lácticas}

A contagem de bactérias láticas foi realizada utilizando-se o Ágar de Man, Rogosa e Sharpe - MRS. As placas foram incubadas à temperatura de $+37^{\circ} \mathrm{C}$ por 5 dias. Foram feitas semeaduras em duplicata para cada diluição, sendo a superfície das placas recoberta com uma sobrecamada do mesmo meio para geração de uma atmosfera microaerófila (SIQUEIRA, 1995). As análises foram realizadas nos dias 0, 3, 7, 14 e 21 após a fabricação do salame.

\section{Micrococcaceae}

A contagem de microrganismos da família Micrococcaceae foi determinada pela técnica em semeadura, utilizando Mannitol Salt Phenol-red ágar (MSA), incubadas a $30{ }^{\circ} \mathrm{C}$ por 72 horas (STAHNKE, 1995), nos dias 0, 3, 7, 14 e 21 após a fabricação do salame.

\section{Staphylococcus $x y$ losus}

O número de células viáveis da cultura iniciadora das amostras foi realizado nos dias 0, 3, 7, 14 e 21 após a fabricação do salame, utilizando a técnica de semeadura em superfície com MSA (Mannitol Salt Phenol-red ágar) e incubadas a $30^{\circ} \mathrm{C}$, por 72 horas (STAHNKE, 1995).

\section{Coliformes totais e fecais}

Para a determinação de coliformes totais foi utilizada a técnica do plaqueamento por incorporação do meio de cultura ágar cristal violeta vermelho neutro bile com incubação a $37^{\circ} \mathrm{C}$, por 24 horas. A partir das placas com desenvolvimento de coliformes totais foram determinados os coliformes fecais em caldo EC (BRASIL, 2003). As análises foram realizadas apenas nos dias 0, 7, 14 e 21 após a fabricação do salame.

\section{Salmonella sp.}

Nos dias 0 e 21 foi realizado um pré-enriquecimento em água peptonada tamponada a $37^{\circ} \mathrm{C}$ por 24 horas a partir de $25 \mathrm{~g}$ 
da mostra. Após esta etapa, foi feito um enriquecimento seletivo em caldo Tetrationato Verde Brilhante e Rappaport Vassiliadis e foram levados à estufa por 24 horas, a $42,5^{\circ} \mathrm{C}$. A partir destes, semeou-se uma alíquota em placas com ágar SS (Salmonella Shiguella) e ágar Rambach, e foram incubados a $37^{\circ} \mathrm{C}$, por 24 horas. As colônias típicas de cada placa foram semeadas em tubos de ágar estoque; caldo ureia; ágar lisina ferro (LIA); ágar citrato de simmons; SIM, para motilidade do indol; ágar tríplice açúcar ferro (TSI), para confirmação bioquímica (BRASIL, 2003).

\section{Staphylococcus coagulase positiva}

A análise de Staphylococcus coagulase positiva foi determinada de acordo com BRASIL (2003), nos dias 0 e 21 após a fabricação do salame, utilizando-se Ágar Baird-Parker a $37^{\circ} \mathrm{C}$, por 48 horas. Em seguida, foi realizado teste bioquímico da coagulase com plasma de coelho.

\subsection{Análises físico-químicas}

\section{Determinação do $p H$}

A medição do $\mathrm{pH}$ foi feita através da homogeneização de dez gramas da amostra com água destilada (1:10 amostra/água). O homogeneizado foi submetido aos eletrodos do pHmetro Digimed, por cinco minutos, quando foi procedida a leitura do pH (TERRA; BRUM, 1988). A determinação do $\mathrm{pH}$ foi realizada nos dias $0,3,7,14$ e 21 após a fabricação dos salames.

\section{Determinação da atividade de água (Aw)}

Para determinação da atividade de água do salame foi utilizado o aparelho Testo 650 (modelo 0563 6501), ocorrendo as determinações nos dias $0,3,7,14$ e 21 após a fabricação dos salames.

\section{Perda de peso}

A perda de peso foi determinada pela diferença de peso existente entre as peças cárneas nos dias $0,3,7,14$ e 21 após a fabricação dos salames.

\section{Avaliação da oxidação lipídica}

As substâncias reativas ao ácido tiobarbitúrico (TBARS) resultantes da oxidação lipídica foram determinadas segundo método descrito por Raharjo, Sofos e Schmidt (1992). Os valores de TBARS foram determinados nos dias 0, 3, 7, 14 e 21 após a fabricação dos salames.

\section{Determinação de nitrito}

A determinação de nitrito das amostras foi realizada conforme método descrito por Association of Official Analytical Chemists (1996), nos dias 0, 7, 14 e 21 após a fabricação do salame.

\section{Determinação de cor}

A determinação da cor foi realizada pelo aparelho Minolta Chroma Meter CR-300 (MINOLTA). Os resultados foram expressos como $L^{*}$ (brilho), $a^{*}$ (índice vermelho) e $b^{*}$ (índice amarelo). As determinações foram realizadas nos dias $0,3,7$, 14 e 21 após a fabricação dos salames.

\subsection{Análise sensorial}

A análise sensorial foi determinada com 21 dias de maturação do salame. Foram avaliadas as características sensoriais de cor, aroma, sabor e textura através do teste de comparação múltipla conforme descrito por Dutcosky (1996). Para a avaliação das amostras, foram utilizados 20 provadores, não treinados, mas consumidores de salame.

\subsection{Análise estatística}

Os dados referentes às análises microbiológicas, físico-químicas e sensoriais foram submetidos à Análise de Variância (ANOVA) ao nível de 5\% de significância, utilizando-se o Teste de Tukey para análises microbiológicas e físico-químicas e o Teste Dunett para análise sensorial (COSTA NETO, 1977) através do pacote estatístico SPSS 8.0.

\section{Resultados e discussão}

\subsection{Análises microbiológicas}

A evolução das bactérias ácido lácticas durante o período de fabricação dos salames é mostrada na Tabela 1. Verifica-se que, no início da fermentação, os tratamentos T1 (controle) e T2 apresentaram uma contagem inicial de aproximadamente 7,0 Log UFC. $\mathrm{mL}^{-1}$, a qual foi significativamente superior aos tratamentos T3 e T4. Observa-se que esta contagem mais elevada encontra-se nos tratamentos inoculados com cultura comercial de Lactococcus lactis ssp. lactis.

Após o $3^{\circ}$ dia de fermentação até o $14^{\circ}$ dia de análise, os tratamentos não diferiram estatisticamente, com uma contagem próxima a 8,0 Log UFC. $\mathrm{mL}^{-1}$, permanecendo praticamente estável até o final da maturação. Apenas o tratamento T4, aos 21 dias, apresentou uma queda de aproximadamente um ciclo logaritmo, diferindo estatisticamente do tratamento T2.

Estes resultados estão de acordo com Rantsiou e Cocolin (2006), que afirmam que, após três dias de fermentação, as bactérias ácido lácticas alcançam uma contagem de 7-8 Log UFC. $\mathrm{mL}^{-1}$, permanecendo relativamente sem alterações, em número, durante todo o período de maturação. Esta alta população de bactérias ácido lácticas produz ácido láctico, ácido acético e possivelmente bacteriocinas que vão inibir o crescimento de bactérias patogênicas, especialmente Staphylococcus aureus (GEISEN; LUCKE; KROCKEL, 1992; LUCKE, 2000).

Foi observado que, no início da fermentação, a contagem da família Micrococcaceae (Tabela 1) nos tratamentos T2 e T4, inoculados com starter de Staphylococcus xylosus nativos, apresentaram uma contagem de 7,0 Log UFC.mL ${ }^{-1}$, significativamente maior que os tratamentos T1 (controle) e T3 (6,0 Log UFC.mL $\left.{ }^{-1}\right)$.

No terceiro dia de fermentação, verifica-se um decréscimo no desenvolvimento da família Micrococcaceae nos tratamentos 
Tabela 1. Análises microbiológicas (Log UFC.mL $L^{-1}$ ) durante o período de fabricação dos salames formulados com diferentes culturas starters.

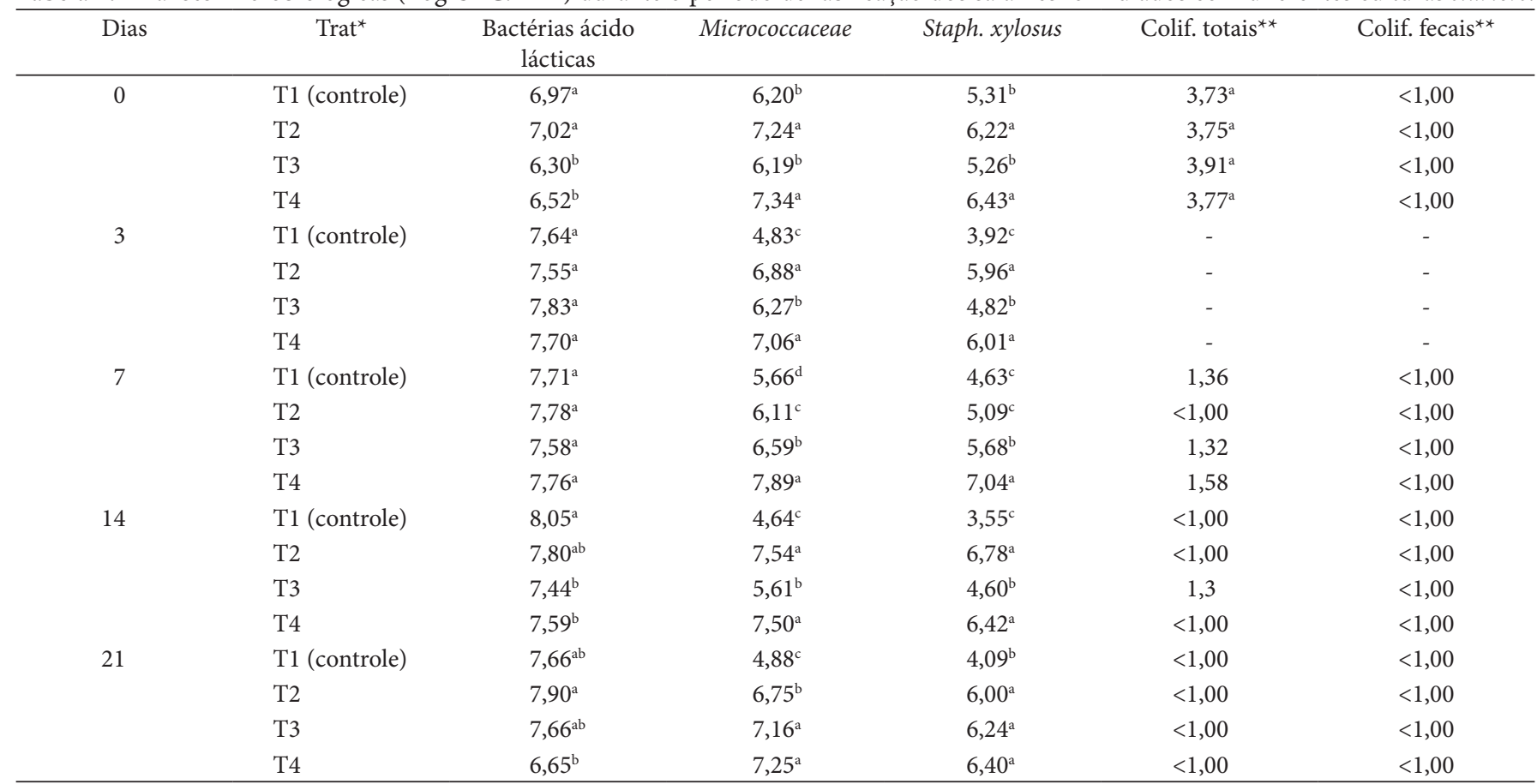

Médias acompanhadas pela mesma letra, na mesma coluna, no mesmo dia, não apresentam diferença significativa (p $\leq 0,05)$ pelo teste de Tukey. ${ }^{\star}$ T1: inoculado com starters comerciais de Staphylococcus xylosus (Floracarn SX, Chr. Hansen) e Lactococcus lactis ssp. lactis (Fund. André Tosello); T2: mistura de Staphylococcus xylosus isolado (CIROLINI et al., 2007a) mais Lactococcus lactis ssp. lactis comercial (Fund. André Tosello); T3: mistura de Lactococcus lactis ssp. lactis isolado (CIROLINI et al., 2007b) mais Staphylococcus xylosus comercial (Floracarn SX, Chr. Hansen) e T4: inoculado com starters isolados de Staphylococcus xylosus (CIROLINI et al., 2007a) e Lactococcus lactis ssp. lactis (CIROLINI et al., 2007b). ${ }^{\star * A n a ́ l i s e ~}$ de coliformes totais e fecais não foi realizada no $3^{\circ}$ dia de fermentação.

T1, T2 e T4, que permanece até o final da maturação, sendo mais destacado no tratamento $\mathrm{T} 1$ (controle) com valor final de 4,88 Log UFC. $\mathrm{mL}^{-1}$, diferindo estatisticamente dos outros tratamentos. Provavelmente este decréscimo na contagem de Micrococaceae deve-se ao baixamento do $\mathrm{pH}$ durante o processo de maturação dos salames.

Estes resultados estão de acordo com Casaburi et al., (2007), que realizaram um trabalho semelhante com o isolamento de cepas de Staphylococcus xylosus de salames do sul da Itália, que foram adicionados em salames e observaram que a contagem inicial de Micrococcaceae foi de 6 a 7 Log UFC. $\mathrm{mL}^{-1}$, sendo que, após 5 dias de fermentação, houve um decréscimo para 5 Log UFC.mL ${ }^{-1}$, afetado pela acidificação. Também Lizaso, Chasco e Beriain (1999) e Samelis et al. (1998) consideram que a acidificação é a causa principal da inibição do crescimento de Micrococcaceae na maturação de salames.

Já no tratamento T3, observa-se que houve um aumento de um ciclo logaritmo aos 21 dias de maturação. Trabalho realizado por Cocolin et al. (2001) também demonstrou um constante crescimento da família Micrococacceae durante a maturação de salames tipo Italiano.

Em relação à contagem de Staphylococcus xylosus (Tabela 1), verifica-se que, no início da fermentação, os tratamentos T2 e T4 inoculados com Staphylococcus xylosus nativos apresentaram uma contagem de 6,0 Log UFC.mL $\mathrm{m}^{-1}$, significativamente maior que os tratamentos T1 e T3 (5,0 Log UFC.mL $\left.{ }^{-1}\right)$.
No terceiro dia de fermentação, todos os tratamentos apresentaram uma queda na contagem. Stahnke (1995) cita que a sobrevivência de Staphylococcus xylosus é reduzida pela sensibilidade ao ácido produzido pelas bactérias ácido lácticas durante a alta temperatura de fermentação.

Essa queda permaneceu até o $21^{\circ}$ dia de maturação nos tratamentos T1, T2 e T4, com destaque para o T1 (controle) que apresentou uma diferença significativa em relação aos outros tratamentos (4,09 Log UFC. $\left.\mathrm{mL}^{-1}\right)$. Já no tratamento T3, observou-se que houve um aumento de um ciclo logaritmo. Fontán et al. (2007) obtiveram contagem de Staphylococcus de 2,36 a 4,74 Log UFC. $\mathrm{mL}^{-1}$ em salames coletados com 20-30 dias de maturação.

Os valores iniciais de coliformes totais (Tabela 1) foram baixos, demonstrando uma boa qualidade higiênico-sanitária da matéria-prima. Os coliformes totais foram progressivamente eliminados em todos os tratamentos durante a fabricação. Estes resultados ressaltam a rápida ação inibidora das culturas starters frente aos microrganismos indesejáveis. Também podemos observar que, durante todo o período de fabricação, não foi detectada, em nenhum tratamento, a presença de coliformes fecais.

Em relação à contagem de Staphylococcus coagulase positiva e Salmonella realizada no início e no final da fabricação do salame, esses microrganismos não foram encontrados em nenhum tratamento (dados não apresentados). 


\subsection{Análises físico-químicas}

A evolução do $\mathrm{pH}$ durante o período de fabricação dos salames é mostrada na Figura 1. Observa-se que durante os primeiros 3 dias de fabricação, houve uma diminuição nos valores de $\mathrm{pH}$ em todos os tratamentos. Essa queda ocorreu fundamentalmente devido ao acúmulo de ácido láctico, formado pela ação das bactérias ácido lácticas sobre os carboidratos presentes na massa cárnea, o qual irá refletir no efeito protetor contra microrganismos indesejáveis, conversão e estabilização da cor e formação de compostos desejáveis de sabor e aroma. (TERRA, 2003).

Nos tratamentos T1, T2 e T4 após os 3 dias de fermentação, a queda nos valores de $\mathrm{pH}$ permaneceu. No tratamento T1, o decréscimo do $\mathrm{pH}$ continuou até o final da maturação, enquanto que, após o $14^{\circ}$ dia de fermentação, os tratamentos T2 e T4 apresentaram uma elevação do $\mathrm{pH}$ até o final da maturação dos salames. Isto pode ser atribuído à produção de amônia e outros compostos tais como peptídios, aminoácidos, aldeídos, aminas e ácidos graxos provindos da atividade proteolítica (MAURIELLO et al., 2004).

O tratamento T3, nos dias 7 e 14 da fermentação, apresentou uma elevação do $\mathrm{pH}$, vindo posteriormente a decrescer. Resultados semelhantes foram encontrados por Sawitzki (2000), o salame inoculado com Lactococcus lactis ssp. lactis apresentou no $14^{\circ} \mathrm{e} 21^{\circ}$ dias de fabricação um acréscimo nos níveis de $\mathrm{pH}$ e, após este período, o salame inoculado demonstrou redução do $\mathrm{pH}$, evidenciando-se ainda o efeito acidificante no salame inoculado.

Nos 4 tratamentos analisados, os valores finais de $\mathrm{pH}$ variaram entre 4,87 e 5,48. Estes valores estão de acordo com Ambrosiadis et al. (2004), que destacam que o $\mathrm{pH}$ de salames tradicionais varia entre 4,67 a 6,09.

A atividade de água diminuiu em todos os lotes durante o processamento dos salames (Figura 2). Esta redução pode ser atribuída ao decréscimo nos valores de $\mathrm{pH}$, pois a capacidade de retenção de água das proteínas da carne é diminuída quando o $\mathrm{pH}$ se aproxima do seu ponto isoelétrico, acelerando a desidratação e, consequentemente, a diminuição da $\mathrm{Aw}$ (CHASCO; LIZASO; BERIAIN, 1996).

O tratamento $\mathrm{T} 4$ apresentou atividade de água significativamente menor que os demais tratamentos no final do processo de fabricação. Os valores finais ficaram entre 0,80 e 0,87 , semelhantes aos resultados expressos por Cavenaghi e Oliveira (1999), que destacam que, nos salames tipo Italiano nacionais, a Aw fica em torno de 0,816 e 0,868 .

A média da perda de peso ficou em torno de $43,26 \%$ (Figura 3), estando esse valor um pouco acima da faixa de 30 a 40\%, considerada ideal para os produtos fermentados secos (RUST, 1994). Valores semelhantes foram encontrados por Garcia-Varona et al. (2000) no processamento de salame tipo Italiano, com uma perda de peso da ordem de $44 \%$. Também Reis e Soares (1998) obtiveram valores entre 38,4 e $43,7 \%$ em salames coloniais.

O teste de TBARS é o método mais usual para acompanhar a evolução da oxidação lipídica em carnes e produtos cárneos. As

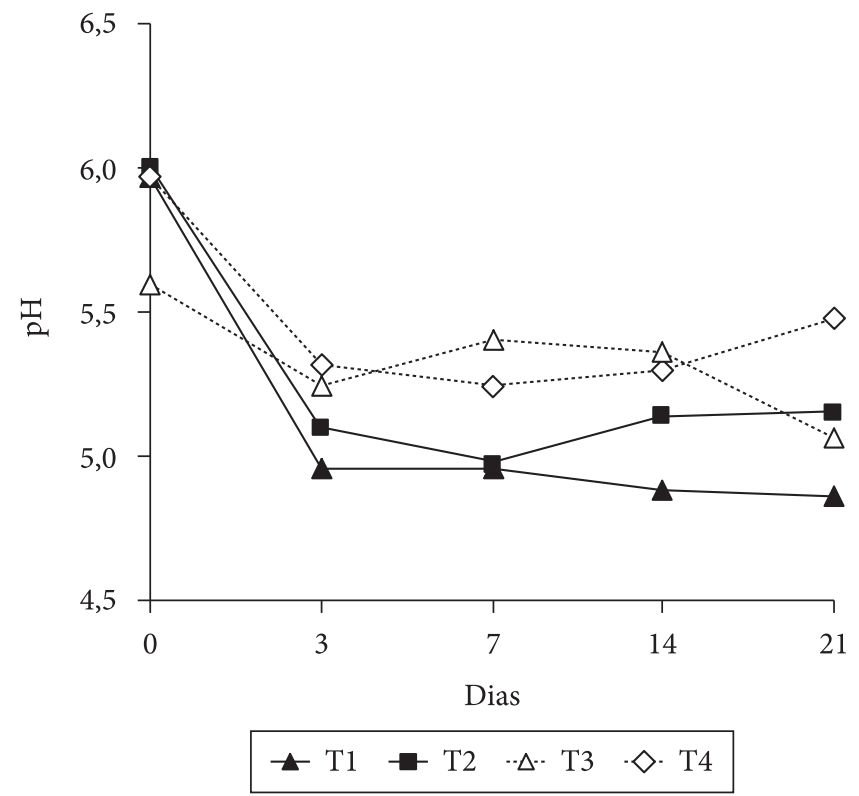

Figura 1. Evolução do $\mathrm{pH}$ dos salames formulados com diferentes culturas starters. T1: inoculado com starters comerciais de Staphylococcus xylosus (Floracarn SX, Chr. Hansen) e Lactococcus lactis ssp. lactis (Fund. André Tosello); T2: mistura de Staphylococcus xylosus isolado (CIROLINI et al., 2007a) mais Lactococcus lactis ssp. lactis comercial (Fund. André Tosello); T3: mistura de Lactococcus lactis ssp. lactis isolado (CIROLINI et al., 2007b) mais Staphylococcus xylosus comercial (Floracarn SX, Chr. Hansen) e T4: inoculado com starters isolados de Staphylococcus xylosus (CIROLINI et al., 2007a) e Lactococcus lactis ssp. lactis (CIROLINI et al., 2007b).

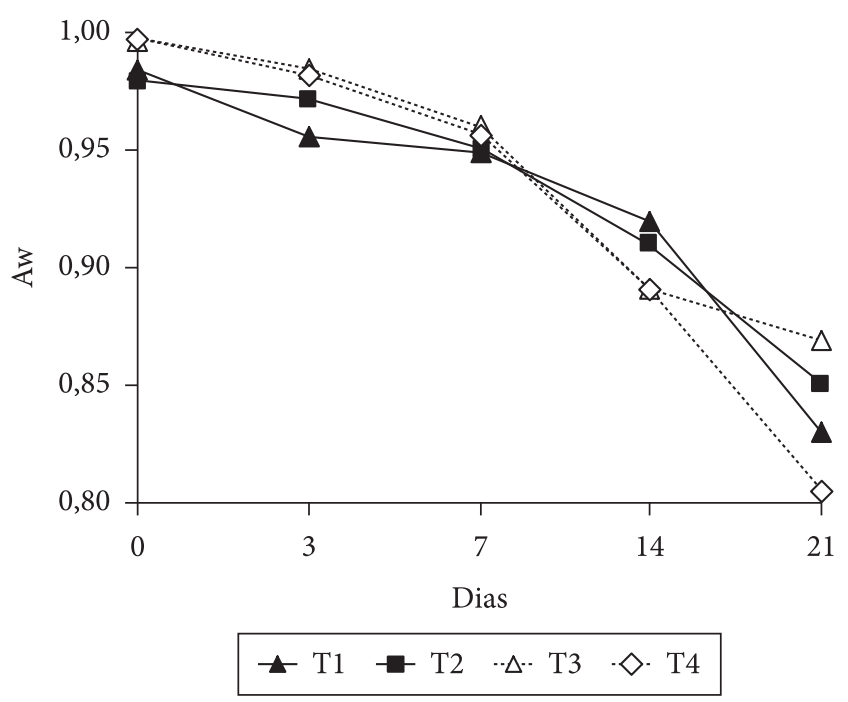

Figura 2. Evolução da atividade de água (Aw) dos salames formulados com diferentes culturas starters. T1: inoculado com starters comerciais de Staphylococcus xylosus (Floracarn SX, Chr. Hansen) e Lactococcus lactis ssp. lactis (Fund. André Tosello); T2: mistura de Staphylococcus xylosus isolado (CIROLINI et al, 2007a) mais Lactococcus lactis ssp. lactis comercial (Fund. André Tosello); T3: mistura de Lactococcus lactis ssp. lactis isolado (CIROLINI et al, 2007b) mais Staphylococcus xylosus comercial (Floracarn SX, Chr. Hansen) e T4: inoculado com starters isolados de Staphylococcus xylosus (CIROLINI et al, 2007a) e Lactococcus lactis ssp. lactis (CIROLINI et al, 2007b). 
mudanças nos valores de TBARS foram acompanhadas durante todo o período de fabricação do salame (Figura 5).

No início da fabricação, os valores de TBARS dos tratamentos não apresentaram diferença estatística. Entretanto, no $7^{\circ}$ dia de fermentação, o tratamento T1 apresentou um grande aumento no valor de TBARS, diferindo estatisticamente dos outros tratamentos até o final da fabricação. O tratamento T3 também teve uma elevação no valor de TBARS no $14^{\circ}$ dia de fabricação, mantendo essa diferença estatística até o final da maturação.

Já os tratamentos T2 e T4, que contêm cepas de Staphylococcus xylosus isoladas, apresentaram valores de TBARS estatisticamente menores que os outros tratamentos a partir do 14 ${ }^{\circ}$ dia. Barriére et al. (2001) destacam que os Staphylococcus apresentam atividade catalase importante na decomposição do peróxido de hidrogênio e para prevenir a oxidação lipídica. Como cita Hammes (1990), os microrganismos isolados de produtos tradicionais são mais promissores para o uso como culturas starters, pois se adaptam melhor ao ambiente da carne e são capazes de dominar a microflora dos produtos.

Os valores de nitrito estão expostos na Figura 4. Pode-se observar que os valores iniciais de nitrito estavam entre 99,34 e 133,65 ppm, sendo que, no $7^{\circ}$ dia de fermentação, houve uma grande redução em seus valores. No $21^{\circ}$ dia de fabricação, observa-se que não houve diferença estatística entre os tratamentos, ficando em torno de 3,28 e 6,09 ppm.

Estes valores estão de acordo com a Portaria $n^{\circ} 1004$ de 11/12/98 do Ministério da Saúde, que permite nível máximo residual de nitrito de 0,015 g.100 g ${ }^{-1}$, ou seja, 150 ppm (BRASIL,1998).

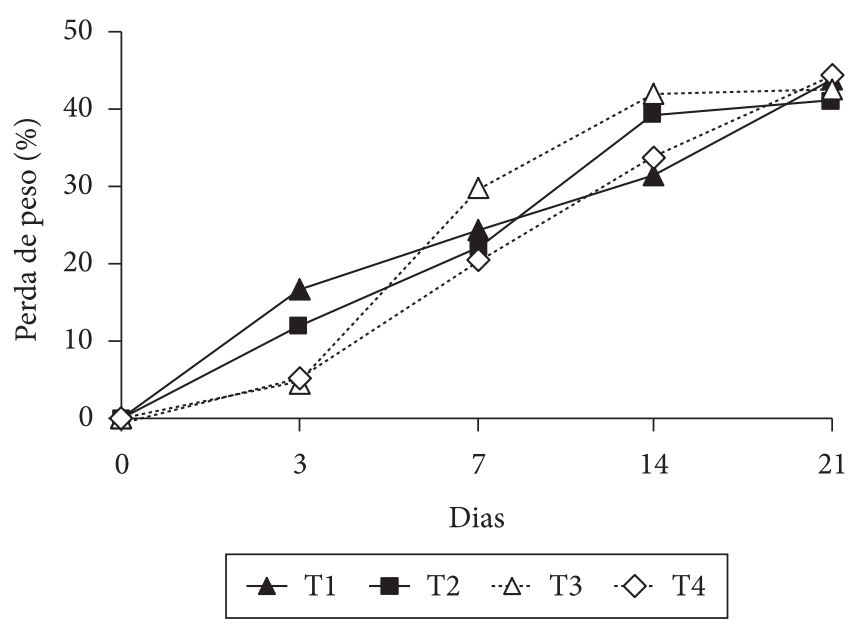

Figura 3. Evolução da perda de peso dos salames formulados com diferentes culturas starters. T1: inoculado com starters comerciais de Staphylococcus xylosus (Floracarn SX, Chr. Hansen) e Lactococcus lactis ssp. lactis (Fund. André Tosello); T2: mistura de Staphylococcus xylosus isolado (CIROLINI et al., 2007a) mais Lactococcus lactis ssp. lactis comercial (Fund. André Tosello); T3: mistura de Lactococcus lactis ssp. lactis isolado (CIROLINI et al., 2007b) mais Staphylococcus xylosus comercial (Floracarn SX, Chr. Hansen) e T4: inoculado com starters isolados de Staphylococcus xylosus (CIROLINI et al, 2007a) e Lactococcus lactis ssp. lactis (CIROLINI et al., 2007b).
Campbell-Platt e Cook (1995) destacam que menos de $50 \mathrm{mg} \cdot \mathrm{kg}^{-1}$ de nitrito são suficientes para a obtenção da cor característica de cura para embutidos fermentados. Essa quantidade deve ser atingida antes da queda de $\mathrm{pH}$, provocada pelo crescimento de bactérias lácticas, uma vez que a enzima nitrato redutase bacteriana tem atividade insignificante em valores de $\mathrm{pH}$ menores que 5,4.

Os valores da determinação da cor dos salames durante a fabricação encontram-se na Tabela 2. Os valores de $L^{\star}$ (brilho) diminuíram em todos os tratamentos ao longo dos 21 dias de fabricação. No início da fermentação, o tratamento T1 (controle) apresentou uma diferença significativa em relação aos tratamentos T2 e T4. No final da maturação, os tratamentos não apresentaram diferença significativa. De acordo com Bozkurt e Bayram (2006), este decréscimo representa a formação da cor escura em decorrência de reações de escurecimento. Semelhantemente, Kayaardi e Gök (2003) verificaram que os valores de $L^{*}$ de salames geralmente decrescem durante o período de maturação. Casaburi et al. (2007) analisaram a cor de salames elaborados com cepas de Staphylococcus xylosus artesanais do sul da Itália e os valores de $L^{\star}$ também decresceram durante os 38 dias de análise.

Os valores de $\mathrm{a}^{\star}$ (índice de vermelho) aumentaram durante todo o período de fabricação. No início da fermentação, o tratamento T3 apresentou o maior valor $(17,42)$, diferindo estatisticamente dos outros tratamentos. No final da maturação, o tratamento T2 e T3 não apresentaram diferença estatística

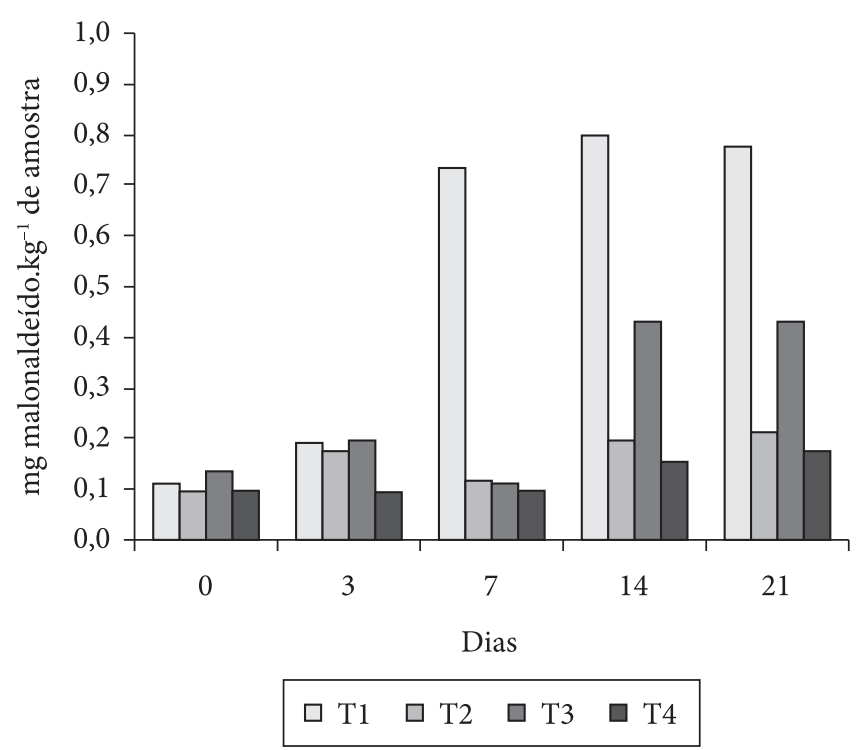

Figura 4. Valores médios de TBARS dos salames formulados com diferentes culturas starters. T1: inoculado com starters comerciais de Staphylococcus xylosus (Floracarn SX, Chr. Hansen) e Lactococcus lactis ssp. lactis (Fund. André Tosello); T2: mistura de Staphylococcus xylosus isolado (CIROLINI et al., 2007a) mais Lactococcus lactis ssp. lactis comercial (Fund. André Tosello); T3: mistura de Lactococcus lactis ssp. lactis isolado (CIROLINI et al., 2007b) mais Staphylococcus xylosus comercial (Floracarn SX, Chr. Hansen) e T4: inoculado com starters isolados de Staphylococcus xylosus (CIROLINI et al., 2007a) e Lactococcus lactis ssp. lactis (CIROLINI et al., 2007b). 


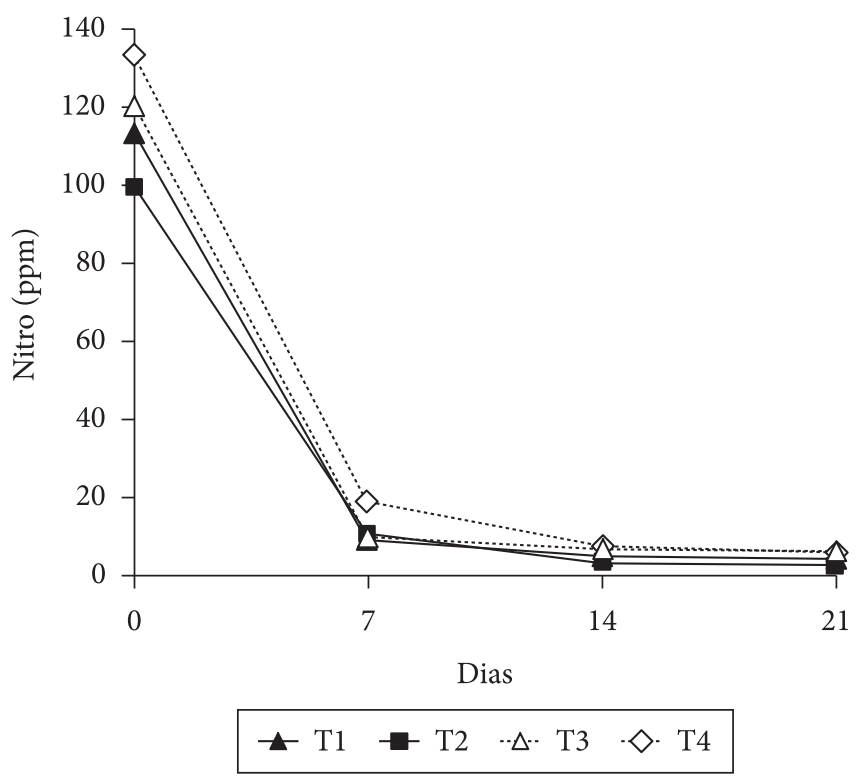

Figura 5. Valores médios do teor de nitrito dos salames formulados com diferentes culturas starters. T1: inoculado com starters comerciais de Staphylococcus xylosus (Floracarn SX, Chr. Hansen) e Lactococcus lactis ssp. lactis (Fund. André Tosello); T2: mistura de Staphylococcus xylosus isolado (CIROLINI et al., 2007a) mais Lactococcus lactis ssp. lactis comercial (Fund. André Tosello); T3: mistura de Lactococcus lactis ssp. lactis isolado (CIROLINI et al., 2007b) mais Staphylococcus xylosus comercial (Floracarn SX, Chr. Hansen) e T4: inoculado com starters isolados de Staphylococcus xylosus (CIROLINI et al., 2007a) e Lactococcus lactis ssp. lactis (CIROLINI et al., 2007b).

do tratamento T1 (controle), que apresentou o maior valor $(22,30)$, e nem do T4, que apresentou o menor valor $(18,48)$. Durante os primeiros dias de fermentação, o óxido nítrico já presente na carne combina-se com a mioglobina produzindo a nitrosomioglobina (LUCKE, 1994). Como esse pigmento tem coloração vermelha, os valores de $\mathrm{a}^{\star}$ aumentam durante a elaboração do salame.

Os valores de $b^{*}$ (índice de amarelo) diminuíram em todos os tratamentos durante a fabricação, sendo que, no início da fermentação, foi observada uma diferença significativa do tratamento T3 em relação aos outros tratamentos. No final do período da maturação, os tratamentos não diferiram estatisticamente. Estes resultados concordam com os dados obtidos por Perez-Alvarez et al. (1999), que observaram a diminuição dos valores de $b^{*}$ de salames durante a fermentação e maturação, atribuindo este decréscimo ao consumo de oxigênio pelos microrganismos e a consequente diminuição da oximioglobina, a qual contribui para a coloração amarela.

\subsection{Análise sensorial}

Os valores médios para os quesitos de cor, odor, sabor e textura encontram-se na Tabela 3. Em relação à cor apenas, o tratamento $\mathrm{T} 4$ diferiu estatisticamente do tratamento $\mathrm{T} 1$ (controle), representado na escala como regularmente melhor que o padrão. Nos atributos odor e sabor, o tratamento T4 também diferiu estatisticamente do tratamento T1, enquanto
Tabela 2. Valores médios da determinação de cor dos salames formulados com diferentes culturas starters expressos como $\mathrm{L}^{\star}$ (brilho), $\mathrm{a}^{*}$ (índice vermelho) e $\mathrm{b}^{*}$ (índice amarelo).

\begin{tabular}{clcrr}
\hline Dias & Tratamentos* & $\mathrm{L}^{*}$ & $\mathrm{a}^{\star}$ & $\mathrm{b}^{*}$ \\
\hline 0 & T1 (controle) & $59,02^{\mathrm{a}}$ & $12,40^{\mathrm{b}}$ & $10,29^{\mathrm{b}}$ \\
& T2 & $52,76^{\mathrm{b}}$ & $13,00^{\mathrm{b}}$ & $9,70^{\mathrm{b}}$ \\
& T3 & $55,40^{\mathrm{ab}}$ & $17,42^{\mathrm{a}}$ & $11,58^{\mathrm{a}}$ \\
& T4 $326^{\mathrm{b}}$ & $13,82^{\mathrm{b}}$ & $9,74^{\mathrm{b}}$ \\
& T1 (controle) & $56,17^{\mathrm{a}}$ & $18,79^{\mathrm{b}}$ & $9,52^{\mathrm{b}}$ \\
& T2 & $50,41^{\mathrm{b}}$ & $17,52^{\mathrm{b}}$ & $8,98^{\mathrm{b}}$ \\
& T3 & $53,04^{\mathrm{ab}}$ & $21,22^{\mathrm{a}}$ & $11,02^{\mathrm{a}}$ \\
& T4 & $50,23^{\mathrm{b}}$ & $17,07^{\mathrm{b}}$ & $9,19^{\mathrm{b}}$ \\
& T1 (controle) & $51,04^{\mathrm{a}}$ & $19,75^{\mathrm{ab}}$ & $9,13^{\mathrm{b}}$ \\
& T2 & $49,34^{\mathrm{ab}}$ & $18,39^{\mathrm{b}}$ & $8,79^{\mathrm{b}}$ \\
& T3 & $48,93^{\mathrm{ab}}$ & $21,76^{\mathrm{a}}$ & $10,05^{\mathrm{a}}$ \\
& T4 & $47,11^{\mathrm{b}}$ & $17,40^{\mathrm{b}}$ & $7,88^{\mathrm{c}}$ \\
& T1 (controle) & $49,90^{\mathrm{a}}$ & $21,85^{\mathrm{a}}$ & $9,06^{\mathrm{ab}}$ \\
& T2 & $44,12^{\mathrm{b}}$ & $19,80^{\mathrm{b}}$ & $7,87^{\mathrm{bc}}$ \\
& T3 & $46,71^{\mathrm{ab}}$ & $21,74^{\mathrm{a}}$ & $9,90^{\mathrm{a}}$ \\
& T4 14 & $46,81^{\mathrm{ab}}$ & $17,83^{\mathrm{c}}$ & $7,63^{\mathrm{c}}$ \\
& T1 (controle) & $44,02^{\mathrm{a}}$ & $22,30^{\mathrm{a}}$ & $7,89^{\mathrm{a}}$ \\
& T2 & $41,51^{\mathrm{a}}$ & $19,88^{\mathrm{ab}}$ & $7,56^{\mathrm{a}}$ \\
& T3 & $44,90^{\mathrm{a}}$ & $21,78^{\mathrm{ab}}$ & $8,65^{\mathrm{a}}$ \\
& T4 & $42,86^{\mathrm{a}}$ & $18,48^{\mathrm{b}}$ & $7,56^{\mathrm{a}}$ \\
\hline
\end{tabular}

Médias acompanhadas pela mesma letra, na mesma coluna, no mesmo dia, não apresentam diferença significativa $(\mathrm{p} \leq 0,05)$ pelo teste de Tukey. ${ }^{*} \mathrm{~T} 1$ : inoculado com starters comerciais de Staphylococcus xylosus (Floracarn SX, Chr. Hansen) e Lactococcus lactis ssp. lactis (Fund. André Tosello); T2: mistura de Staphylococcus xylosus isolado (CIROLINI et al., 2007a) mais Lactococcus lactis ssp. lactis comercial (Fund. André Tosello); T3: mistura de Lactococcus lactis ssp. lactis isolado (CIROLINI et al., 2007b) mais Staphylococcus xylosus comercial (Floracarn SX, Chr. Hansen) e T4: inoculado com starters isolados de Staphylococcus xylosus (CIROLINI et al., 2007a) e Lactococcus lactis ssp. lactis (CIROLINI et al., 2007b).

Tabela 3. Valores médios de notas para cor, odor, sabor e textura dos salames.

\begin{tabular}{lcccc}
\hline & Cor & Odor & Sabor & Textura \\
\hline T1 (controle) & $4,0^{\mathrm{b}}$ & $4,0^{\mathrm{b}}$ & $4,1^{\mathrm{b}}$ & $4,0^{\mathrm{a}}$ \\
T2 & $3,6^{\mathrm{b}}$ & $4,3^{\mathrm{b}}$ & $4,4^{\mathrm{b}}$ & $4,3^{\mathrm{a}}$ \\
T3 & $4,3^{\mathrm{b}}$ & $4,5^{\mathrm{ab}}$ & $4,8^{\mathrm{ab}}$ & $4,7^{\mathrm{a}}$ \\
T4 & $5,2^{\mathrm{a}}$ & $5,2^{\mathrm{a}}$ & $5,5^{\mathrm{a}}$ & $5,0^{\mathrm{a}}$ \\
\hline
\end{tabular}

Médias acompanhadas pela mesma letra, na mesma coluna, não apresentam diferença significativa $(\mathrm{p} \leq 0,05)$ pelo teste de Dunnett. ${ }^{\star} \mathrm{T} 1$ : inoculado com starters comerciais de Staphylococcus xylosus (Floracarn SX, Chr. Hansen) e Lactococcus lactis ssp. lactis (Fund. André Tosello); T2: mistura de Staphylococcus xylosus isolado (CIROLINI et al., 2007a) mais Lactococcus lactis ssp. lactis comercial (Fund. André Tosello); T3: mistura de Lactococcus lactis ssp. lactis isolado (CIROLINI et al., 2007b) mais Staphylococcus xylosus comercial (Floracarn SX, Chr. Hansen) e T4: inoculado com starters isolados de Staphylococcus xylosus (CIROLINI et al., 2007a) e Lactococcus lactis ssp. lactis (CIROLINI et al., 2007b).

que o tratamento T3 não diferiu dos outros tratamentos. Em relação à textura não foi observada diferença estatística entre os tratamentos. De modo geral, o tratamento T4, elaborado com culturas starters nativas, apresentou melhores resultados que os salames elaborados com culturas starters comerciais em todos os quesitos analisados. 


\section{Conclusões}

A contagem da família Micrococcaceaee Staphylococcus xylosus no tratamento T1 (controle) apresentou valores menores que nos outros tratamentos. Na contagem de bactérias ácido lácticas, coliformes totais e fecais, os tratamentos não apresentaram diferença estatística do controle.

Os salames elaborados com diferentes culturas starters apresentaram uma queda de $\mathrm{pH}$ significativa e também uma redução na atividade de água, garantindo uma segurança microbiológica aos produtos.

Em relação à oxidação lipídica, os tratamentos que continham cepas de Staphylococcus xylosus isolados de salames artesanais apresentaram valores menores que os outros tratamentos.

Já análises de perda de peso, nitrito e os valores de cor $\mathrm{L}^{\star} \mathrm{e}$ $b^{\star}$ não apresentaram diferença estatística entre os tratamentos, apenas o valor de $\mathrm{a}^{\star}$ no tratamento T1 (controle) apresentou valor maior, diferindo estatisticamente do tratamento T4.

Os salames elaborados com Staphylococcus xylosus e Lactococcus lactis ssp. lactis, ambos isolados, apresentaram melhores resultados sensoriais, quando comparados com salames elaborados com culturas starters comerciais.

Portanto, a adição de culturas starters nativas pode ser utilizada na elaboração de salames, proporcionando produtos seguros e com flavor diferenciado.

\section{Referências bibliográficas}

AMBROSIADIS, J.et al. Physicochemical, microbiological and sensory attributes for the characterization of greek traditional sausages. Meat Science, v. 66, n. 2, p. 279-287, 2004.

ASSOCIATION OF OFFICIAL ANALYTICAL CHEMISTS. Official methods of analysis of AOAC internacional. 16. ed. 1996. v. 2.

BARRIÉRE, C. et al. Roles of superoxide dismutase and catalase of Staphylococcus xylosus in the inhibition of linoleic acid oxidation. FEMS Microbiology Letters, v. 201, n. 2, p. 181-185, 2001.

BRASIL. Ministério da Saúde. Regulamento Técnico Atribuição de Funções de Aditivos, Aditivos e seus Limites Máximos de uso para a Categoria 8 - Carne e Produtos Cárneos. Portaria no 1004, 11 de dezembro de 1998. Diário Oficial da União, Brasília, DF, 14 dez. 1998, p. 28.

BRASIL. Ministério da Agricultura, Pecuária e Abastecimento. Métodos Analíticos Oficiais para Análise. Microbiológicas para Controle de Produtos de Origem Animal e Água. Instrução Normativa $n^{\circ}$ 62, 26 de agosto de 2003. Diário Oficial da União, Brasília, DF, 18 set. 2003, p. 14.

BOZKURT, H.; BAYRAM, M. Colour and textural attributes of sucuk during ripening. Meat Science, v. 73, n. 2, p. 344-350, 2006.

CAMPBELL-PLATT, G.; COOK, P. E. Fermented meats. London: Blackie Academic \& Professional, 1995.

CASABURI, A. et al. Biochemical and sensory characteristics of tradicional fermented sausages of Vallo di Diano (southern Italy) as affected by the use of starter cultures. Meat Science, v. 76, n. 2, p. 295-307, 2007.

CAVENAGHI, A. D.; OLIVEIRA, M. N. Influência de algumas características físico-químicas e sensoriais na qualidade de salame tipo italiano fabricado no Brasil. Revista Nacional da Carne, v. 23, n. 263 , p. $44-48,1999$.
CHASCO, J.; LIZASO, G.; BERIAIN, M. J. Cured colour development during sausage processing. Meat Science, v. 44, n. 3, p. 203-211, 1996.

CIROLINI, A. et al. Isolamento e caracterização de Staphylococcus xylosus de salames coloniais. In: SIMPÓSIO LATINO AMERICANO DE CIÊNCIA DE ALIMENTOS, 7., 2007. Anais... Campinas: Systemica Tecnologia, 2007a. CD-ROM.

CIROLINI, A. et al. Lactococcus lactis ssp. lactis fermentado em meio de cultura à base de plasma suíno. In: SIMPÓSIO LATINO AMERICANO DE CIÊNCIA DE ALIMENTOS, 7., 2007. Anais... Campinas: Systemica Tecnologia, 2007b. CD-ROM.

COCOLIN, L. et al. A novel polymerase chain reaction (PCR) denaturing gradient gel electrophoresis (DGGE) for the identification of Micrococcaceae strains involved in meat fermentations: its application to naturally fermented Italian sausages. Meat Science, v. 58, n. 1, p. 59-64, 2001.

COSTA NETO, P. L. O. Estatística. São Paulo: Edgard Blücher, 1977. $264 \mathrm{p}$.

DROSINOS, E. H. et al. Characterization of the microbial flora from a traditional Greek fermented sausage. Meat Science, v. 69, n. 2, p. 307-317, 2005.

DUTCOSKY, S. D. Análise Sensorial de Alimentos. Curitiba: Champagnat, 1996.

ESSID, I. et al. Characterization and technological properties of Staphylococcus xylosus strains isolated from a Tunisian traditional salted meat. Meat Science, v. 77, n. 2, p. 204-212, 2007.

FONTÁN, M. C. G. et al. Microbiological characteristics of "androlla", a Spanish tradicional pork sausage. Food Microbiology, v. 24, n. 1, p. 52-58, 2007.

GARCIA-VARONA, M. et al. Characterization of Micrococcaceae isolated from different varieties of chorizo. International Journal of Food Microbiology, v. 54, n. 3, p. 189-195, 2000.

GEISEN, R.; LUCKE, F. K.; KROCKEL, L. Starter and protective cultures for meat and meat products. Fleischwirtschaft, v. 72, n. 6, p. 898-984, 1992.

GRECO, M. et al. Evolution and identification of lactic acid bacteria isolated during the ripening of Sardinian sausages. Meat Science, v. 69, n. 4, p. 733-739, 2005.

HAMMES, W. P. Bacterial starter cultures in food production. Food Biotechnology, v. 4, n. 1, p. 383-387, 1990.

KAYAARDI, S.; GÖK, V. Effect of replacing beff fat with olive oil on quality characteristics of turkish soudjouk (sucuk). Meat Science, v. 66, n.1, p. 249-257, 2003.

LIZASO, G.; CHASCO, J.; BERIAIN, J. Microbiological and biochemical changes during ripening of salchichon, a Spanish dry cured sausage. Food Microbiology, v. 16, n. 3, p. 219-228, 1999.

LUCKE, F. K. Fermented meat products. Food Research International, v. 27, n. 3, p. 299-307, 1994.

LUCKE, F. K. Utilization of microbes to process and preserve meats. Meat Science, v. 56, n. 2, p.105-115, 2000

MAURIELLO, $\mathrm{G}$ et al. Isolation and technological properties of coagulase negative staphylococci from fermented sausages of southern Italy. Meat Science, v. 67, n. 1, p.149-158, 2004.

MORETTI, V. A. et al. Chemical and microbiological parameters and sensory attributes of a typical sicilian salami ripened in different conditions. Meat Science, v. 66, n. 4, p. 845-854, 2004.

PEREZ-ALVAREZ，J. A.; SAYES-BARBARE, M. E.; FERNANDEZ-LOPEZ, J.; ARANDA-CATALA, V. Physicochemical characteristics of Spanish-type dry-cured sausage. Food Research International, v. 32, n. 9, p. 599-607, 1999. 
RAHARJO, S., SOFOS, J. N., SCHMIDT, G. R. Improved speed, specifity and limit of determination of na aqueous acid extration thiobarbiituric acid- $\mathrm{C}_{18}$ method for mesuring lipid peroxidation in beef. Journal Agricultural Food Chemistry, v. 40, n. 2, p. 2182-2185, 1992.

RANTSIOU, K.; COCOLIN, L. New developments in the study of the microbiota of naturally fermented sausages as determined by molecular methods: A review. International Journal of Food Microbiology, v. 108, n. 2, p. 255-267, 2006.

REIS, A. G. B.; SOARES, G. J. D. Salame colonial processado com carne suína e ovina. Revista Brasileira de Agrociência, v. 2, n. 2, p. 115-120, 1998.

RUST, R. E. Productos Embutidos. In: PRICE, J. F.; SCHWEIGERT, B. S. (Eds.) Ciencia de La Carne y de Productos Carnicos. 2. ed. Zaragoza: Acribia, 1994. p. 415-440.

SAMELIS, J. et al. Stability and safety of traditional Greek salmi - a microbiological ecology study. International Journal of Food Microbiology, v.44, n.1-2, p. 69-82, 1998.
SAWITZKI, M. C. Caracterização de Bactérias Ácidos Láticas isolsadas de Salames Artesanais e aplicadas como culturas iniciadoras em Salame Tipo Italiano. 2000. 53 p. Dissertação (Mestrado) - Universidade Federal de Santa Maria, Santa Maria, 2000.

SIQUEIRA, R. S. Manual de microbiologia de Alimentos. Brasília, DF: Embrapa, 1995.

STAHNKE, L. Dried sausages fermented with Staphylococcus xylosus at different temperatures and with different ingredient levels: chemical and bacteriological data. Meat Science, v. 41, n. 2, p.179-191, 1995.

TERRA, N. N. Apontamentos de Tecnologia de Carnes. São Leopoldo: Unisinos, 2003.

TERRA, N. N.; BRUM, M. A. R. Carne e Seus Derivados. São Paulo: Nobel, 1988.

VURAL, H. The use of commercial starter cultures in the production of turkish semi-dry fermented sausages. Zeitschrift Lebensm Unters Forsch A, v. 207, n. 5, p. 410-412, 1998. 